\title{
GROWTH RESPONSE OF PINUS DENSIFLORA SEEDLINGS INOCULATED WITH THREE INDIGENOUS ECTOMYCORRHIZAL FUNGI IN COMBINATION
}

\author{
Dalong M.1; Luhe W.1,Guoting Y.2; Liqiang M. ${ }^{2 *}$; Chun L. ${ }^{3}$
}

${ }^{1}$ College of Geographical Sciences, Harbin Normal University, Harbin, Heilongjiang Province, China, $150025 ;{ }^{2}$ College of Forestry, Northeast Forestry University, Harbin, Heilongjiang Province, China. 150040; ${ }^{3}$ Forestry Diseases and Pest Control Station of Heilongiiang Province, Harbin, Heilongjiang Province, China. 150040.

\begin{abstract}
Pinus densiflora seedlings were inoculated with three indigenous ectomycorrhizal fungi (Cenococcum geophilum, Rhizopogon roseolus and Russula densifolia) in single-, two-, and three-species treatments. After 8 months, the colonization rates of each ectomycorrhizal species, seedling growth and the nutrition were assessed in each treatment. $P$. densiflora seedlings inoculated with different ECM species composition showed an increase in height and basal diameter and improved seedling root and shoot nutrition concentrations compared to control treatment. Generally, combined inoculation had a more positive influence on the seedlings than the single inoculation. The three-species inoculation presented the highest growth and basal diameter and concentration of most nutrients except potassium. In conclusion, the results provided strong evidence for benefits of combined inoculation with the indigenous ectomycorrhizal fungi on $P$. densiflora seedlings under controlled conditions.
\end{abstract}

Key words: Ectomycorrhizal fungi, Pinus densiflora, Combined inoculation

\section{INTRODUCTION}

Ectomycorrhizal (ECM) fungi usually improve the uptake and transfer of nutrients and water to the host plant, especially under unfavourable environmental conditions. In addition, the ECM mantle acts as a physical barrier avoiding water losses and root desiccation (16).

In many temperate and boreal forest ecosystems the dominant tree species present form ectomycorrhizal associations. The host-fungus symbiotic compatibility, the ease of inoculum production and the fungal ecological adaptability to the transplantation site are some important criteria to select ECM fungi for nursery mycorrhization programmes (9). Inoculation with selected ectomycorrhizal (ECM) fungi has often been identified as a promising nursery cultural practice to improve the quality of the seedling stock and its performance after out-planting (14). As this is a highly resource-consuming effort, the seedlings should be inoculated with ECM fungi best suited to host tree species and that rapidly colonize their roots, and which are well adapted to the environmental conditions of

*Corresponding Author. Mailing address: College of Forestry, Northeast Forestry University, Harbin, Heilongjiang Province, China. 150040.; Tel.: 86-045182191829.; E-mail: mlq0417@ @otmail.com 
the planting site (11).

Several authors have reported positive effects on seedling growth and survival in the field environment after nursery inoculation with different mycorrhizal fungi $(1,4,7)$. However, Browning and Whitney (3) found that five inoculated fungi persisted on the root systems of jack pine and black spruce seedlings for two growing seasons, but declined after the second year. The results are consistent with the results of previous studies (13), which reported that inoculated ECM fungi are gradually replaced by indigenous ECM fungi after outplanting in the field. Fangfuk et al. (6) test the ability of Astraeus hygrometricus to form ectomycorrhizae with seedlings of Pinus densiflora in vitro. Guerin-Laguette et al. (8)'s research on the inoculation with Tricholoma matsutake on $P$. densiflora seedling showed that inoculation significantly stimulated total seedling dry weight compared to the control treatments.

The research on the inoculation with indigenous ECM fungi based the investigation of community structure of the host tree seedling ECM is still rare. The main aim of the present work was to manipulate ECM species composition by inoculating the indigenous Cenococcum geophilum, Rhizopogon roseolus and Russula densifolia onto Pinus densiflora seedlings in all possible combinations to check the influence of inoculation on seedling growth and nutrition.

\section{MATERIALS AND METHODS}

\section{Fungal material}

Fungal isolates of Rhizopogon roseolus (Corda) Th. Fr. (GU143029) and Russula densifolia (Secr.) Gill. (GU143030) were obtained from sporocarps collected in an afforestated, approximately 50-year-old stand, where Pinus densiflora Sieb. et Zucc was the dominant tree species in Jidong County of Hei Longjiang Province, China $\left(45^{\circ} 07^{\prime} \mathrm{N}, 131^{\circ} 15^{\prime} \mathrm{E}\right)$. Cenococcum geophilum Fr. (GU138766) had been cultured in our laboratory though the source was not clear. The three ECM fungal types were the most abundant ones colonizing in the P. densiflora 1 5year old seedlings according to below-ground ECM community investigation (unpublished).

Pure cultures of these fungi were grown on plates of modified Melin-Norkrans (MMN) agar medium. After 1 month, mycelial plugs approximately $1 \times 1 \mathrm{~cm}$ were placed in modified MMN liquid medium in 200-ml Erlenmeyer flasks and incubated for 1 month at $25^{\circ} \mathrm{C}$ in the dark.

\section{Plant material and inoculation}

P. densiflora seeds were surface sterilized with $30 \%$ $\mathrm{H}_{2} \mathrm{O}_{2}$ for 20 min and rinsed 4-5 times with sterile deionized water. Inoculum was prepared in the plastic chamber $(15 \mathrm{~cm}$ diameter and $40 \mathrm{~cm}$ length), each containing $500 \mathrm{~g}$ substrate. They were then germinated on sterilized substrate (sand : vermiculite : peat moss $=3: 2: 1$ volume). The experiment was conducted in a growth chamber with the following controlled conditions: light intensity of $400 \mu \mathrm{mol} \mathrm{m}^{-2} \mathrm{~s}^{-1}$, a 16 : $8 \mathrm{~h}$ light : dark cycle, temperature ranging from 20 to $25^{\circ} \mathrm{C}$, approximately $70 \%$ relative humidity. When the seedlings were 3 month old they were inoculation with the ECM fungi. They were subjected to seven treatments, with 30 seedlings for each treatment. 30 seedlings were not inoculated with any ECM fungi (control treatment). The single-species treatment had each species inoculated individually, the two-species treatment had all pair-wise inoculations of the three species, and the three-species treatment had all three species inoculated together. The inoculation was performed by injecting $30 \mathrm{ml}$ of each ECM fungal liquid inoculum into each seedling root. The control seedlings received $30 \mathrm{ml}$ of modified MMN liquid medium with no fungal mycelium. To avoid potential contamination from other ECM species, the growth chamber was previously checked to be free of ECM inoculum.

\section{Seedling harvest}


After eight months of growing, the $P$. densiflora seedlings were harvested and the root systems were gently Dalong, M. et al.

running tap water. For all seedlings, height and root-collar diameter were measured. The percentage of ectomycorrhizal colonization of each sample of root pieces was determined for each treatment and the control (number of root pieces with ectomycorrhizal structure/total number of root pieces $\times 100 \%$ ) under a stereomicroscope. All live ECM root tips were separated from the root system. The ECM root tips of each treatment were then flash frozen in liquid nitrogen, lypholized for $48 \mathrm{~h}$ and weighed. The shoot and remaining non-ECM portion of seedling root system were individually oven-dried at $60^{\circ} \mathrm{C}$ for $48 \mathrm{~h}$ and then weighed. The $\mathrm{N}$ content was determined by the Kjeldahl method (5), P by colorimetry (12) and $\mathrm{K}$ by flame photometry (15).

\section{Statistical analysis}

One-way analysis of variance (ANOVA) was used to analyze data with the SPSS 14.0 software package. Differences among treatments were separated by the least significant difference test $(\mathrm{P} \leq 0.05)$.

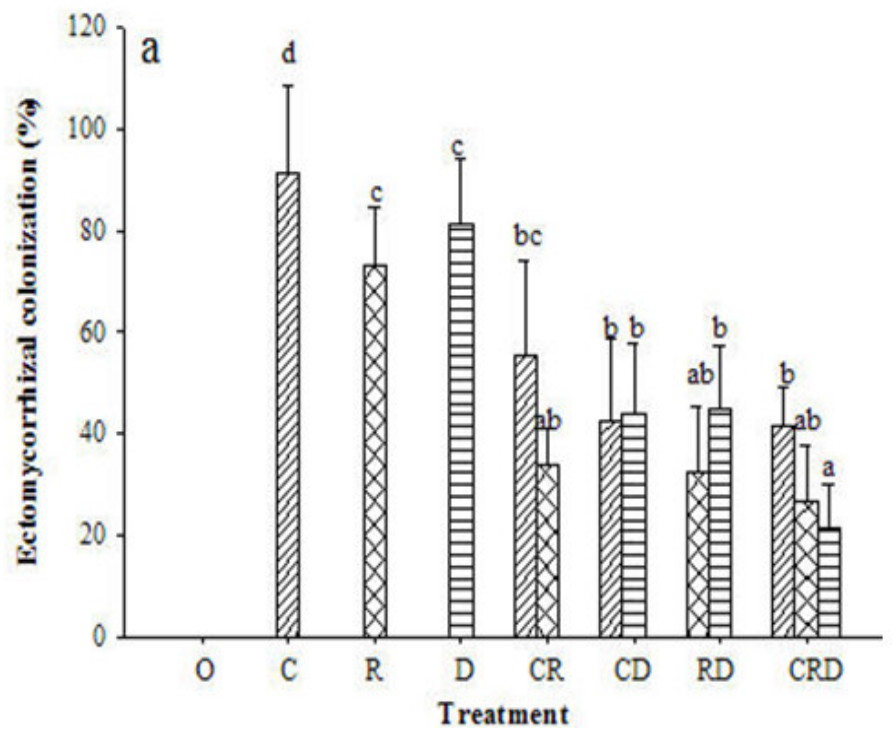

\section{RESULTS}

In the single-species treatments, $C$. geophilum colonization percentage was significantly higher than $R$. roseolus and $R$. densifolia. In the two-species treatments of $C$. geophilum and R. roseolus, C. geophilum was dominant. When $C$. geophilum and $R$. densifolia were inoculated together, no significant difference was found. In the treatments of $R$. roseolus and $R$. densifolia, $R$. densifolia was higher than $R$. roseolus. In the three-species treatment, C. geophilum showed the highest colonization percentage whereas $R$. densifolia showed the lowest (Fig. 1a). The ECM biomass followed the same trend of colonization percentage (Fig. 1b). Control treatment seedlings had no ECM colonization on all 30 replicates.

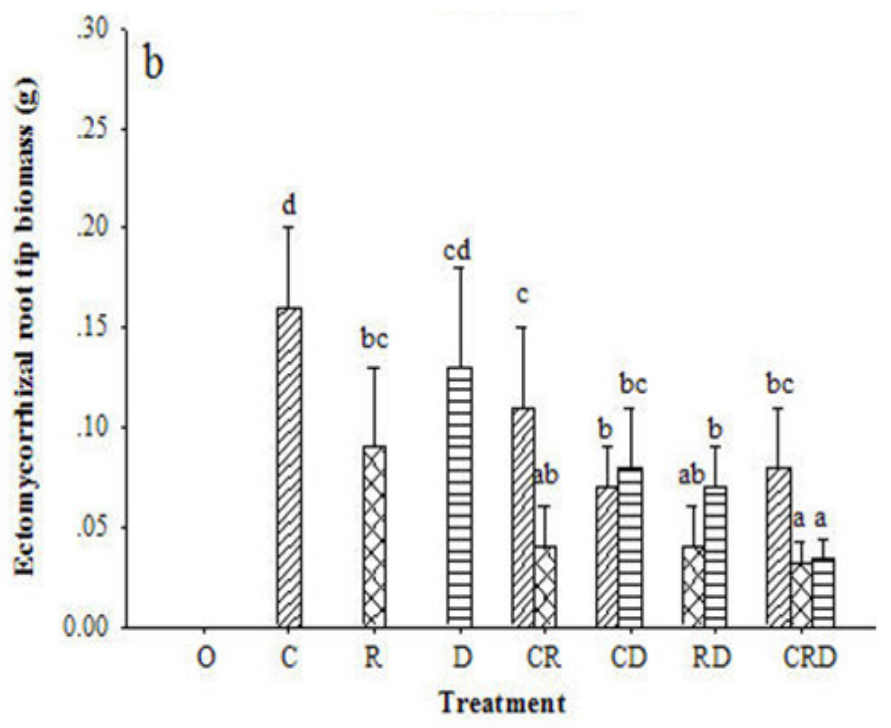


Figure 1. Effect of different inoculation combinations on ectomycorrhizal colonization (a) and ectomycorrhizal root tip biomass (b) of $P$. densiflora seedlings. Different letters denote significant differences among inoculation treatments according to the LSD test $(\mathrm{P} \leq 0.05)$. Control (O), Cenococcum geophilum (C), Rhizopogon roseolus (R), Russula densifolia (D).

P. densiflora seedlings inoculated with different ECM species composition generally showed an increase in height and basal diameter compared to control treatment. The height of seedlings inoculated with $C$. geophilum $+R$. roseolus $+R$. densifolia was significantly higher than the seedlings from other treatments (Fig. 2a). Seedling basal diameter increased significantly by inoculation with the species composition of $C$. geophilum $+R$. roseolus and C. geophilum $+R$. roseolus $+R$. densifolia with respect to other treatments (Fig. 2b). Control treatment seedlings had no ECM colonization on all 30 replicates. The root biomass of control treatment was significantly higher than other treatments. However, the root biomass of seedlings inoculated with $R$. roseolus was significantly higher than that of the inoculated with $C$. geophilum $+R$. densifolia (Fig. 3a). Shoot biomass of the seedlings inoculated with $C$. geophilum $+R$. densifolia and $C$. geophilum $+R$. roseolus $+R$. densifolia was significantly higher than other treatments (Fig. 3b).
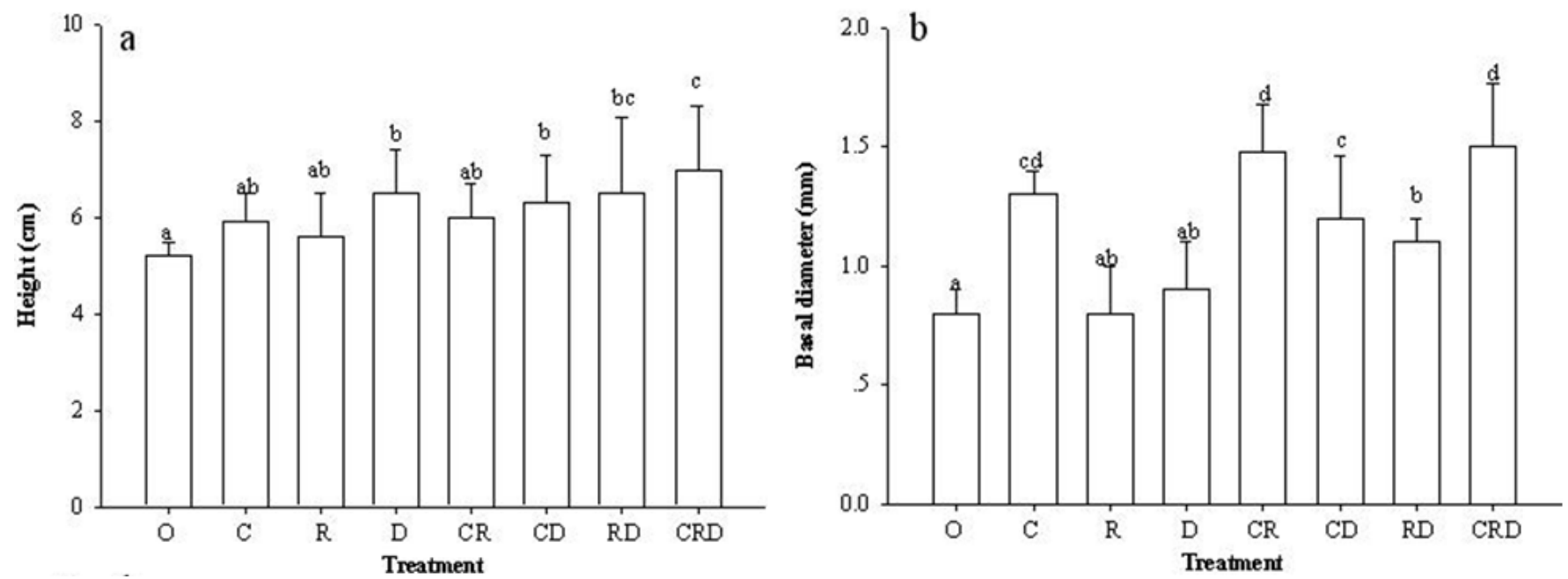

Figure 2. Effect of inoculation with different ectomycorrhizal fungi on the height (a) and basal diameter (b) of $P$. densiflora seedlings. Different letters denote significant differences among inoculation treatments according to the LSD test ( $\leq 0.05)$. Control $(\mathrm{O})$, Cenococcum geophilum (C), Rhizopogon roseolus (R), Russula densifolia (D). 

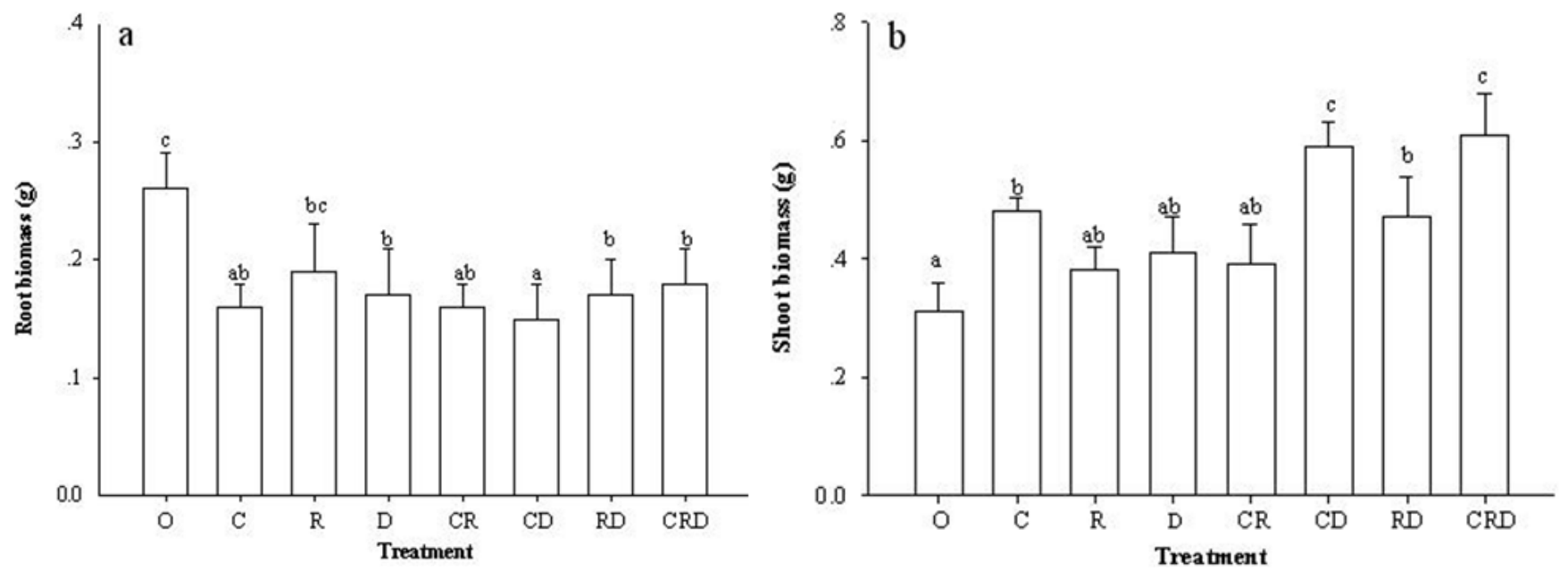

Figure 3. Effect of inoculation with different ectomycorrhizal fungi on the root biomass (a) and shoot biomass (b) of $P$. densiflora seedlings. Different letters denote significant differences among inoculation treatments according to the LSD test (P $\leq 0.05)$. Control $(\mathrm{O})$, Cenococcum geophilum (C), Rhizopogon roseolus (R), Russula densifolia (D).

Dalong, M. et al.

Indigenous ectomycorrhizal fungi

The content of nutrients in root and shoot of seedlings was modified by inoculation, and variable results were obtained depending on the fungus and the nutrient considered (Table 1). Compared with the control treatment, the content of $\mathrm{N}$ in root was significantly increased by inoculation in all the treatments and this increase was higher with C. geophilum $+R$. roseolus and three-species inoculation. The content of $\mathrm{P}$ was significantly increased by inoculation with three species, and the content of $\mathrm{K}$ was significantly increased in seedlings inoculated with $R$. roseolus and $C$. geophilum $+R$. roseolus. The shoot contents of $\mathrm{N}$ and $\mathrm{P}$ were significantly increased by inoculation with three-species inoculation with respect to controls. Inoculation with all fungi combinations (except $C$. geophilum) increased the content of $\mathrm{K}$ in shoot.

Table 1. Effect of inoculation with different ectomycorrhizal fungi on the content of nutrients in $P$. densiflora seedlings

\begin{tabular}{cccccccccccccc}
\hline Treatment & \multicolumn{3}{c}{ Root } & \multicolumn{3}{c}{ Shoot } & \\
\hline & $\mathrm{N}(\mathrm{mg} / \mathrm{g})$ & & $\mathrm{P}(\mathrm{mg} / \mathrm{g})$ & & $\mathrm{K}(\mathrm{mg} / \mathrm{g})$ & & $\mathrm{N}(\mathrm{mg} / \mathrm{g})$ & & $\mathrm{P}(\mathrm{mg} / \mathrm{g})$ & $\mathrm{K}(\mathrm{mg} / \mathrm{g})$ \\
$\mathrm{O}$ & $6.7 \pm 0.2$ & $\mathrm{a}$ & $1.1 \pm 0.3$ & $\mathrm{a}$ & $5.4 \pm 0.5$ & $\mathrm{a}$ & $8.9 \pm 1.1$ & $\mathrm{a}$ & $1.3 \pm 0.4$ & $\mathrm{a}$ & $7.9 \pm 1.2$ & $\mathrm{ab}$ \\
$\mathrm{C}$ & $11.0 \pm 1.5$ & $\mathrm{c}$ & $1.4 \pm 0.6$ & $\mathrm{ab}$ & $5.8 \pm 0.6$ & $\mathrm{~b}$ & $16.2 \pm 0.9$ & $\mathrm{~cd}$ & $1.7 \pm 0.5$ & $\mathrm{~b}$ & $7.7 \pm 1.6$ & $\mathrm{a}$ \\
$\mathrm{R}$ & $9.7 \pm 0.8$ & $\mathrm{bc}$ & $1.3 \pm 0.4$ & $\mathrm{ab}$ & $6.8 \pm 0.2$ & $\mathrm{c}$ & $9.9 \pm 1.5$ & $\mathrm{ab}$ & $1.8 \pm 0.7$ & $\mathrm{~b}$ & $8.6 \pm 1.3$ & $\mathrm{~b}$ \\
$\mathrm{D}$ & $9.2 \pm 1.1$ & $\mathrm{~b}$ & $1.7 \pm 0.2$ & $\mathrm{~b}$ & $5.4 \pm 0.4$ & $\mathrm{a}$ & $10.7 \pm 0.8$ & $\mathrm{~b}$ & $2.2 \pm 0.6$ & $\mathrm{bc}$ & $8.1 \pm 0.8$ & $\mathrm{ab}$ \\
$\mathrm{CR}$ & $12.1 \pm 1.6$ & $\mathrm{~d}$ & $1.6 \pm 0.3$ & $\mathrm{~b}$ & $6.9 \pm 0.3$ & $\mathrm{c}$ & $14.5 \pm 1.7$ & $\mathrm{c}$ & $1.5 \pm 0.5$ & $\mathrm{ab}$ & $9.2 \pm 1.4$ & $\mathrm{bc}$ \\
$\mathrm{CD}$ & $10.5 \pm 2.4$ & $\mathrm{bc}$ & $1.4 \pm 0.5$ & $\mathrm{ab}$ & $5.5 \pm 0.8$ & $\mathrm{ab}$ & $11.3 \pm 0.6$ & $\mathrm{bc}$ & $1.6 \pm 0.4$ & $\mathrm{ab}$ & $8.5 \pm 1.8$ & $\mathrm{~b}$ \\
$\mathrm{RD}$ & $9.8 \pm 2.9$ & $\mathrm{bc}$ & $1.9 \pm 0.7$ & $\mathrm{bc}$ & $5.9 \pm 0.7$ & $\mathrm{~b}$ & $10.3 \pm 0.5$ & $\mathrm{~b}$ & $2.1 \pm 0.6$ & $\mathrm{bc}$ & $9.6 \pm 0.7$ & $\mathrm{c}$ \\
$\mathrm{CRD}$ & $12.4 \pm 2.8$ & $\mathrm{~d}$ & $2.5 \pm 0.6$ & $\mathrm{c}$ & $6.2 \pm 0.9$ & $\mathrm{bc}$ & $18.4 \pm 1.3$ & $\mathrm{~d}$ & $2.4 \pm 0.9$ & $\mathrm{c}$ & $9.1 \pm 0.5$ & $\mathrm{bc}$
\end{tabular}

Data are mean \pm SD. For each nutrient, different letters denote significant differences among inoculation treatments according to the LSD test (P $\leq 0.05)$. Control (O), Cenococcum geophilum (C), Rhizopogon roseolus (R), Russula densifolia (D).

\section{DISCUSSION}


Our tests show that inoculations with ECM increased seedling growth and content of nutrients in relation with uninoculated control treatment, except the treatment of $R$. densifolia in $\mathrm{K}$ content in root and of $C$. geophilum in $\mathrm{K}$ content in shoot. It is interesting to point out that combined inoculation had a more positive effect on seedling growth and content of nutrients than single inoculation, especially the three-species inoculation. Previous studies have also shown that individual mycorrhizal species can have different effects on their hosts, influence plant performance, and can alter allocation of resources (17). If different mycorrhizal fungi have differential effects on plants and if plants are able to some extent to control mycorrhizal colonization, coexistence of different mycorrhizal fungi could also be explained by Dalong, M. et al.

effects of inoculation with several combinations ECM fungi in the reforestation field.

ECM fungi showed strong physiological variability both within and between species, some species appeared more ecologically adapted to certain sites than other species. To gain maximum benefit from mycorrhizal inoculation, seedlings should be inoculated with fungal symbionts which were the best suited to specific tree species, and which were well adapted to the environmental conditions of the planting site. Thus, controlled mycorrhizal by inoculating nursery-grown seedlings with selected fungal strains was likely to be of great benefit for forest plantations (7). However, mycorrhizal types on Pinus seedlings from a nursery can be completely replaced by indigenous types after transplanting (13). Likewise, new roots of Douglas-fir seedlings inoculated with Laccaria laccata and Hebeloma crustuliniforme were all colonized by indigenous ECM fungi 5 months after transfer to the field (2). Marx and Cordell (10) suggested that for inoculation of seedlings an 'early stage' fungus will be more successful than a 'late stage' fungus and only pioneer fungi were suitable for mycorrhizal inoculation programmes. Therefore, the inoculation with indigenous ECM on the seedlings may facilitate the growth after outplanting. differential effects on plant fitness which support the convenience of mixed ECM inoculation. Therefore a diverse mycorrhizal fungal community might be essential from the seedlings perspective. Wu et al. (18) examined interspecific competition among three ECM species colonizing $P$. densiflora and found that interactions between mycorrhizal fungi can cause some to become dominant and others secondary. The results of our study were similar to their findings. Under the controlled conditions of this experiment, in the three-species inoculations, $C$. geophilum was the most dominant, whereas $R$. densifolia and $R$. roseolus had a smaller colonizing ability. However, the role played by each ECM fungi in the growth and survival of seedlings after outplanting still remains to be defined. Future studies are necessary in order to examine the Indigenous ectomycorrhizal fungi

The seedlings used in reforestation programmes in eastern China are often obtained from bare root nurseries. For that reason, they are usually of a poor quality and the mycorrhizal level in the root systems is deficient or absent. Our results suggest that it may be essential to identify and use more indigenous fungal combinations to maximize inoculation success. The seedlings initially with suitable ectomycorrhizas were able to take the advantage of mycorrhizal root system, and were able to withstand planting stress. This study explored the potential benefits of the inoculation with the indigenous ectomycorrhizal fungi in combinations on $P$. densiflora seedlings. More observations and measurements are, therefore, necessary to elucidate this, and will be done in our experimental plantations in the future.

\section{ACKNOWLEDGEMENTS}

This project was financially supported by the State Forestry Administration Foundation of China (010-41308913).

\section{REFERENCES}

1. Alves, L.; Vetúria, L.; Oliveira; Germano, N.; Filho, S. (2010). Utilization of rocks and ectomycorrhizal fungi to promote growth of eucalypt. Brazilian Journal of Microbiology. 41, 676-684. 
2. Bledsoe, C.S.; Tennyson, K.; Lopushinsky, W. (1982). Survival and growth of outplanted douglas-fir seedlings inoculated with mycorrhizal fungi. Can J For Res. 12, 720-723.

3. Browning, M.H.R.; Whitney, R.D. (1992). Field performance of black spruce and jack pine inoculated with selected species of ectomycorrhizal fungi. Can J For Res. 22, 1974-1982.

4. Díaz, G.; Carrillo, C.; Honrubia, M. (2009). Production of Pinus halepensis seedlings inoculated with the edible fungus Lactarius deliciosus under nursery conditions. New Forests. 38, 215-227.

5. Duponnois, R.; Kisa, M.; Prin, Y.; Ducousso, M.; Plenchette, C.; Lepage, M.; Galiana, A. (2008). Soil factors influencing the growth response of Acacia holosericea A. Cunn. ex G. Don to ectomycorrhizal inoculation. New Forests. 35, 105-117.

6. Fangfuk, W.; Okada, K.; Petchang, R.; To-anun, C.; Fukuda, M.;Yamada, A. (2010) In vitro mycorrhization of edible Astraeus mushrooms and their morphological characterization. Mycoscience. 51, 234-241.

Dalong, M. et al.

ectomycorrhizal fungi-impact on plant performance and ectomycorrhizal community. Mycorrhiza. 12, 337-348.

12. Novozamsky, V.J.G.; Huba, R.; Van Vark, W. (1983). A novel digestion technique for multiple element plant analysis. Commun Soil Sci Plant Anal. 14, 239-249.

13. Quoreshi, A.M.; Piché,Y.; Khasa, D.P. (2008). Field performance of conifer and hardwood species 5 years after nursery inoculation in the Canadian Prairie Provinces. New Forests. 35:235-253.

14. Rincón, A.; Parladé, J; Pera, J. (2007) Influence of the fertilisation method in controlled ectomycorrhizal inoculation of two Mediterranean pines. Annals of Forest Science. 64, 577-583.
7. Garbaye, J.; Churin, J.L. (1997). Growth stimulation of young oak plantations inoculated with the ectomycorrhizal fungus Paxillus involutus with special reference to summer drought. For Ecol Manage. 98, 221-228.

8. Guerin-Laguette, A.; Shindo, K.; Matsushita, N.; Suzuki, K.; Lapeyrie, F. (2004). The mycorrhizal fungus Tricholoma matsutake stimulates Pinus densiflora seedling growth in vitro. Mycorrhiza. 14, 397-400.

9. Jonsson, L.; Dahlberg, A.; Nilsson, M.C. (1999). Continuity of ectomycorrhizal fungi in self-regenerating boreal Pinus sylvestris forests studied by comparing mycobiont diversity on seedlings and mature trees. New Phytol. 142, 151-162.

10. Marx, D.H.; Cordell, C.E. (1989). The use of specific ectomycorrhizas to improve artificial forestation practices. In: Whipps JM, Lumsden RD (Eds.), Biotechnology of Fungi for Improving Plant Growth. British Mycological Society, Cambridge University Press, Cambridge, pp. 1-25.

11. Menkis, A.; Vasiliauskas, R.; Taylor, A.; Stenlid, J. (2007). Afforestation of abandoned farmland with conifer seedlings inoculated with three

Indigenous ectomycorrhizal fungi

15. Ryan, J.; Garabet, S.; Harmsen, K.; Rashid, A. (1996). A soil land plant analysis manual adapted for the West Asia and North Africa regions. ICARDA, Aleppo, Syria.

16. Smith, S.E.; Read, D.J. (1997) Mycorrhizal symbiosis. Academic, Cambridge, UK.

17. Van der Heijden, E.W.; Kuyper, T.W. (2001). Does origin of mycorrhizal fungus or mycorrhizal plant influence effectiveness of the mycorrhizal symbiosis? Plant Soil. 230, 161-174.

18. Wu, B.; Nara, K.; Hogetsu, T. (1999). Competition between ectomycorrhizal fungi in colonizing Pinus densiflora. Mycorrhiza. 9, 151-159. 
